\title{
Phonological Awareness of English Phonemes by Kuwaiti Arabic Speakers with Evidence of Phonemic Hypercorrection
}

\author{
Rahima Akbar*, Hanan Taqi, Nada Al-Gharabally \\ English Department, College of Basic Education, Ardiya, Kuwait \\ Email address: \\ rahima.s.akbar@gmail.com (R. Akbar) \\ ${ }^{*}$ Corresponding author
}

To cite this article:

Rahima Akbar, Hanan Taqi, Nada Al-Gharabally. Phonological Awareness of English Phonemes by Kuwaiti Arabic Speakers with Evidence of Phonemic Hypercorrection. International Journal of Education, Culture and Society. Vol. 5, No. 6, 2020, pp. 126-136.

doi: $10.11648 /$ j.ijecs.20200506.13

Received: October 17, 2020; Accepted: November 2, 2020; Published: November 11, 2020

\begin{abstract}
Research in the area of L2 phonological awareness continues to grow rapidly considering the importance of achieving proficient spoken English and ensuring being understood during communication, but most importantly on guaranteeing learners (worldwide) better professional opportunities. In Kuwait, conversing in English at a level at which the users can understand and be understood has become crucially important, regardless of the field in which the population studies or works. Within such intriguing context of phonological awareness in second language acquisition, the current study investigated the association of English phonemes production and perception by speakers of Kuwaiti Arabic and the main triggers of incorrect production. The present study looked specifically into the phonological errors made by Kuwaiti speakers of English when L1 has a parallel phoneme of only one of the two contrasting L2 phonemes in its L1 phoneme and/or orthography systems. The study was conducted on 244 Kuwaiti male and female participants between the ages of 18 and 30 . The sample answered a 44 words questionnaire consisting of three English phonemes, namely, $/ \mathrm{p} /, / \mathrm{v} / \mathrm{and} / \mathrm{t} / /$ and their counterparts $/ \mathrm{b} /$, /f/ and $/ / /$. The participants were asked to choose the correct sound they hear in word-initial and word-final positions. Findings of the study suggest that many Kuwaiti learners of English found it difficult to identify the English phonemes as a result of a deeper level of complications triggered by the occurrence of contrasting phonemes in both L1 and L2, hypercorrection, and interference of orthography. It is, hence, believed that perception is not the sole reason that causes Arabic learners of English to produce English sounds incorrectly.
\end{abstract}

Keywords: Second Language, Phonological Awareness, Production, Perception, Hypercorrection, Orthography, Sociolinguistics, English, Kuwaiti Arabic

\section{Introduction}

As globalization reaches its peak, English has become a lingua franca worldwide, and as a result, research into second language learning has examined learning from different perspectives; one of the most regularly studied L2 skills is whether L2 learners can acquire the skills to speak (produce) and understand (perceive) L2 phonemes accurately in order to be understood and to understand others [1]. Amongst the most influential theories in that perspective is the claim that successful production and perception of the L2 are affected by the relationship between the phonemes of their native language (L1) and the target language (L2) [2].

Generally, our goal as educators is not to expect our English language learners to achieve near-native English pronunciation since there is a common understanding that it is far more necessary for learner's speech to be intelligible. Yet, educators cannot, and should not, ignore the myriad of pronunciation challenges faced by language learners. A key challenge, for example, is when learners try to make sense of the phonetic and phonological inventory and patterns of the target language (L2, in this case, English), especially when mapped against those that are already established in their mother tongue (L1, Arabic). 
In this respect, many studies have shown that the native language has a distinctive effect on the acquisition of the $2^{\text {nd }}$ language [3]. Several studies researched the question "how the native language plays a role in the phonological presentation of $2^{\text {nd }}$ language sounds?" [4-6]. In her study "The Interrelation between Speech Perception and Phonological Acquisition from Infant to Adult", Brown argues that successful acquisition of L2 phonology depends on the correct perception of the sounds and their contrasts in the target language and vice versa; an integration of speech perception and phonological acquisition process shape the mature phonological system as illustrated below [7].

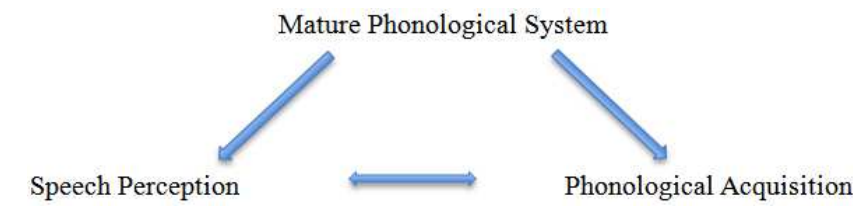

Figure 1. Phonological presentation of L2 sounds [adopted from Brown $2000]$.

In fact, the body of research in the area of L2 acquisition is vast and continues to grow rapidly considering the importance of achieving proficient spoken English and ensuring being understood during communication, but most importantly on guaranteeing learners (worldwide) better professional opportunities.

In Kuwait, the status of English has progressively moved from being a foreign language into the language of advancement and high professional opportunity $[8,9]$. Conversing in English at a level at which the users can understand and be understood has become crucially important in Kuwait, regardless of the field in which the population studies or works. As linguists in the field of ESL, we have noticed that Kuwaitis not only tend to encounter problems in the production of consonants that are missing in their L1 inventory, namely, [p] and [v], but also they tend to be bewildered between the non-existing phonemes and their L1 existing counterparts, despite the manifestation of the latter in Kuwaitis' L1 phonological inventory. In this sense, it is likely to hear Kuwaitis articulating [park] as [bark], yet [ball] as [pall].

The present study is, therefore, an attempt to explore the area of phonological awareness by English users in Kuwait. We mainly focus on whether contrastive consonants that are missing in the speakers' L1 are accurately perceived by the population under study. As such, the contrastive consonants /p/ vs. /b/, /f/ vs. /v/ will be investigated in relation to the most influential theories on L2 phonological awareness. Additionally, / $\mathrm{t} /$ / vs. / $/$ / will be investigated to determine whether L1 orthography influences L2 phonological perception. One of the major objectives in the present study is to verify or refute the claims and predictions presented in the main theories focusing on phonological awareness within the second language acquisition discipline.

\section{Literature Review}

The term phonology is used loosely in L2 acquisition, for the acquisition of phonemic categories, phonological rules, phonetic detail, and perceptual weighting of acoustic cues, among others. According to Isbell perception involves the recognition of a sound as belonging to a phonological category in the aural input, featuring in a learner's underlying phonological system [10]. Production, however, refers to using the oral-articulatory system in speaking. The two components are believed to intuitively come in the order of perception preceding production $[11,12]$.

Our main goal in this research is to explore whether the community under investigation would be influenced by the similarity/dissimilarity conceptualized within the discipline of L2 phonological awareness. We also aim to explore the influence of the concept of hypercorrection and orthography on the L2 phonological realization.

Accordingly, the present study aims to answer the following questions:

How accurate do Kuwaitis perceive L2 phonemes [p], [v] which are non-existent in their L1 phonological inventory?

Does the position of the investigated phonemes affect the accuracy level of their perception?

How does the orthographical system affect the degree of accuracy at which the phoneme [ $\mathrm{t} f]$ is perceived?

Does the profile represented by Kuwaiti ESL learners mirror an instance of hypercorrection?

The study's review of literature is therefore presented in five sub-sections, the first of which focuses on the most influential theories of L2 speech perception. The second explores the influence of orthography on L2 phonological awareness, followed by a third sub-section on the concept of 'hypercorrection' and the way it has been conceptualized in the area of L2 phonological apprehension. The final subsection presents an overview of previous experimental research on English phonological perception by Arab adult learners followed by an overview of the linguistic situation in Kuwait.

\subsection{The Token of Similarity/Dissimilarity in L2 Phonological Awareness}

The concept of similarity/dissimilarity has been repeatedly presented in the most influential theories of L2 phonological awareness. Fledge for instance, proposed the Second Language Model (SLM), arguing that, when learning L2, adults apply a similar process to what children utilize when acquiring their L1, including the learning of accurate perception of the properties of L2 speech sounds and the formation of new phonetic categories [12, 13]. In this regard, SLM postulated several predictions in the perception of L2 phonemic representations, the first of which is that learners relate positional allophones in L2 to the nearest positional allophone in L1 [14], referring to those linked sounds between L1 and L2 as 'diaphones', which would more likely resemble one another in the production of L2 sounds.

A second prediction states that bilinguals sometimes establish a new phonetic category representation for sounds in the L2. If it corresponds to the native speakers' categorical representation, then the L2 sound will be produced 
accurately. SLM also proposed, the greater the dissimilarity of the perceived phonetic L2 sound from the closest L1 sound, the more likely a new category will be created for an L2 sound [15]. The concept explained why Japanese learners of English will discern cross-language phonetic differences between English 'l' and 'r' but not between Japanese 'r' and English ' $r$ ' despite similar symbolizations [16].

From a similar point of view, the Perceptual Assimilation Model for second language learning (PAM-L2) assumes that listeners tend to assimilate L2 to L1 sounds that they perceive as most similar. Thus, PAM proposes that accuracy in the discrimination of L2 sounds depends on how they are assimilated to L1 sounds. As such, successful L2 sound discrimination is the basis for L2 perceptual success. If two L2 sounds are assimilated to two different L1 sounds, or phonemes, discrimination is predicted to be excellent, whereas if two sounds are assimilated to a single L1 category, discrimination will be poor. However, such perceptual assimilation does not seem to be static. Best suggest that exposure to L2 input (i.e., experience with the L2) may lead to the reorganization of perceptual assimilation patterns [17].

L2 Linguistic Perception Model (L2LP) proposes that during L2 initial stages the learner automatically creates a "copy" of the L1 perception [18]. This copy of the L1 system evolves with higher exposure to the L2. During the L2 development stage, L2 learners can access L1 learning mechanisms - namely, auditory-guided category formation and lexicon-guided boundary shifting for phonological categories (Full Access). A third scenario would occur when L2 learners constitute two separate sets of perceptual categories for L1 and L2 reaching a level of Full Proficiency. The development and stability of L2 and L1 are predicted when both are used regularly. The model argues that this is likely to happen when L1 and L2 are learned in controlled language modes [18, 19]; when the learners are conditioned to think that the only language they hear is either L1 or L2 but never both.

\subsection{Orthographic vs. Acoustic Input}

During the first decade of the twenty-first century, several studies started to look into the effects of orthography on L2 phonological representation, many of which confirmed significant findings, connecting orthographic presentations to L2 phonology, including perception, production, and acquisition of L2 sounds and words.

A connection between L1/L2 orthography and inaccurate L2 phonological presentation was first established in the work of Pennington [20]. According to Basetti, there is evidence that L2 orthographic input affects L2 production (both spoken and written). Hence, L2 orthographic input interacts with the acoustic input and affects L2 learners' mental representations of L2 phonology (perception) [21]. As such, inaccurate perception in turn results in non-target like realizations of phonemes (production), which can neither be attributed to the influence of learners' L1 phonology nor universals of phonological acquisition based on the theoretical SLA arena.

Several studies proposed that when learners transfer their knowledge of L1's inventories of graphemes and their representative sound correspondences into L2 in an attempt to make sense of unfamiliar sound-spelling correspondences, the result is non-target production or accented $2^{\text {nd }}$ language speech [22-24]. For example, Zampini found that English L1/Spanish L2 pronounced Spanish words with a /v/ (nonexisting in Spanish) in reading and speaking instead of $a / b /$ as a result of its orthographic representation in the English language (due to being more exposed to the English orthography) [25].

More evidence of orthography-induced phoneme substitution has been found in the Italian learners of English. They pronounce 'thin' as 'tin' because the phoneme $/ \theta /$ does not exist in Italian phonology, realized as the phoneme $/ \mathrm{t} /$. The finding indicates that some substitutions are caused by the L2 orthographic representation, because learners incorrectly assimilate an L2 phoneme with an L1 phoneme when they are represented by the same grapheme (i.e. letter or letter combination). As such, Italian ESL learners

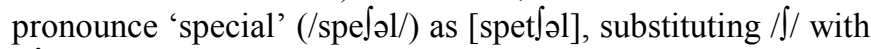
$/ \mathrm{t} \mathrm{J}$, because in their L1 orthography the grapheme <ci> represents the phoneme $/ \mathrm{t} \int /[26]$.

It has also been argued that when L1 and L2 have different degrees of phoneme-grapheme transparency (English is less transparent than Arabic), orthographical representations might have a negative effect on learners' phonological awareness of L2, especially when the L2 writing system is entirely novel to L2 learners [27].

\subsection{Hypercorrection in SLA}

The term 'hypercorrection' has been introduced in both $1^{\text {st }}$ language acquisition as well as in $2^{\text {nd }}$ language learning. The concept has been established by Labov as a sociolinguistic concept which involves a speaker's awareness of language varieties that are associated with differing degrees of prestige. Speech communities are expected to perform a prestigious linguistic form in contexts where the form originally should not be employed, to gain the form's associated prestige [28].

The concept has been perceived from another angle within the area of SLA. In some studies, hypercorrection has been paired with 'crosslinguistic influence'. Odlin identified hypercorrection as an instance of L2 learners' overreaction to a particular influence from the speakers' mother tongue, causing L2 errors in SLA [29]. For example, Janda present that French learners of English incorrectly produce initial /h/ in words that begin with a vowel in English [30]. Due to the absence of the phoneme $/ \mathrm{h} /$ in word-initial position, the production of an h-initial English word like head as [ $\varepsilon \mathrm{d}]$ by a native speaker of French can be attributed to crosslinguistic influence. Yet, Eckman et el. argue against the point, explaining that a French learner's realization of English ache as [hek] is not a case of direct crosslinguistic influence, since, if the L1 pattern was followed, there would be no initial $/ \mathrm{h} /$, and the form would follow an L2 rule [31]. As such, forms 
such as [hek] should be considered as hypercorrection errors, not cross-linguistic transfer.

From another point of view, Siegel argues that hypercorrection in SLA is equivalent to overgeneralization [32]. In that sense, hypercorrection results from the overproduction of a specific L2 linguistic form, within contexts where the form should not be applied. Echman et al. logically challenge equating the term of hypercorrection with overgeneralisation, arguing that SLA data is full of cases of overgeneralisations that cannot be linked to any of the L2 structures. For instance, in the previous example of French realisation of vowels in an initial word position as $/ \mathrm{h} /,(*[\mathrm{hek}]$ for [ache]), French learners of English would be incorrectly applying a newly learned phonemic structure that should neither be associated with the overproduction of a phoneme categorization of the L2 (English in this case) nor based on the L1 (French prohibition of $/ \mathrm{h} / \mathrm{at}$ an initial word position) [31].

Echman et al. have additionally claimed a third commonplace view of the concept of 'hypercorrection', where L2 learners produce hypercorrection errors as they mimic a prestige language variety, not in absolute terms. That is to say, in the case of French learners of English, the target language (English) is considered to be more prestigious than French, in the sense that the target language is the variety to be reproduced if learners seek to speak that language intelligibly [31]. Shafiro et al. reinforce a similar account, arguing that the value accorded to the phoneme $/ \mathrm{h} /$ by francophones is because it is more prestigious to speak English like a native speaker, and because it is stigmatized not to produce/h/, since hdeletion is one of the most salient and least favoured features of francophone speech. It is therefore postulated that within an L2 learning context, the TL is considered to be more prestigious than the NL, even if not absolutely so [33].

\subsection{English Speech Perception by Adult Arabic Learners of English}

Arabic speakers are claimed to represent one of the largest groups of L2 English users, where English is "generally viewed positively and as the language of technology, progress, and the future" [34]. Research in the field has mainly focused on the abilities of early bilingual English-Arabic speakers of different dialects [35] in identifying American English vowels and consonants. Overall vowel identification for the Arabic speakers was $70 \%$, while consonant identification accuracy reached as high as $95 \%$. The results also indicate that the perception of English consonants tends to be less confusing than the English vowel system.

Language-specific experience in Arabic as an L1 tends to influence the perception and production of L2 (English) phonemic contrasts, typically when one or both phonemes in the contrast are realised differently or do not occur in the learner's L1. With adult English learners, more inaccurate phonological perception and production is anticipated [36].

It is worth recalling that the Arab world has been linguistically characterized as diglossic in nature, whereby one formal language (MSA) is utilized systematically in all their official written documents. Different nations in different
Arab countries use their distinctive vernaculars (dialects), which are grammatically and lexically less complex, representing oral forms, are hardly ever written, and enjoy varying degrees of intelligibility with both MSA and one another [37]. Within this framework, several phonemes, that the spoken variety represents, are completely absent in the written orthography. For instance, the phonemes / $/ \mathrm{t} /$ and $/ \mathrm{g} /$ have no equivalent letters in the Arabic orthography, and hence, substituted by / $/$ and /q/ when transcribed in social media chats recently representing Arabs' written vernaculars. As such, the situation tends to be even more complicated amongst Arabic L1 learners of English.

Thus, Arabic learners' difficulties with English vowels and consonants might vary according to their dialect background. This is because different dialects vary in their phonological inventories, based on which similarity/dissimilarity concept would be processed differently too. According to [36], when the learner is faced with novel phonemes, s/he might establish one that closely matches an L1 category. Such problematic phonological aspects tend to be even more confusing when paralleled with certain orthographic cues (for example, a missing phoneme in written Arabic even though it exists in the spoken variety of the learners). The study also confirms the perceptionproduction link. The study additionally reflects on whether practice makes perfect in both perception and production. Results show a good level of perception skills but not as much in the production, providing partial support for the importance of explicit feedback in both perception and production, only when conditioned with domain-specific training.

Confusions which Saudi Arabic speakers presented in the case of consonant contrasts showed problems in the representations of $/ \mathrm{J} /-/ \mathrm{d} \int /, / \mathrm{J} /-/ \mathrm{t} \int /, / \mathrm{m} /-/ \mathrm{n} /-/ \mathrm{y} /$, all of which were explained concerning the phonemic inventory in their L1 compared to that of the L2. That is, they find the phonemes that do not occur in their L1 harder to perceive and produce than those that do occur in their L1.

\subsection{The Current Study; Learners of English in Kuwait}

Kuwaitis are ordinarily exposed to formal (however basic and limited it may be) English by the age of 6 when it is taught to them in elementary Arabic public schools. They are usually taught by English teachers whom themselves are set back by pronunciation and grammatical errors in English primarily due to phonetic interference from their mother tongue (Arabic). But it has to be said that these learners of English are exposed to informal English long before 6 years of age through a more influential source: the media [38]. Children as young as 3 years old, sit glued to TV sets viewing cartoons and Disney movies in English. By the time they are in their early teens, they have already established the idea that part developing a 'trendy' identity may require speaking the language that most of the music and film industry use: American English. And yet, admittedly, not all Kuwaitis who have been exposed to English at school or via media seem to have the same linguistic grasp of the language, especially with regards to the pronunciation of English sounds that are nonexistent in the Arabic phonetic 
inventory (mentioned earlier). Therefore, this category of EFL learners - although, may in rare circumstances, be verbally fluent in American English - normally, lack English proficiency in both pronunciation and syntax [39].

However, to present a more balanced linguistic landscape of English in Kuwait, it has to be noted that a sizable proportion of Kuwaitis have been educated in English and American private schools and/or sent abroad to English speaking countries to study. They represent a notable portion of the fluent English speaking population in Kuwait [38, 40]. But since the majority of the English learners in Kuwait are of the former (Arabic public schools) category, the present study favors involving them as the sample of participants in need of investigation. Therefore, the following study graduates and undergraduates from all the public and private universities of Kuwait ensuring their schooling was mainly in the Arabic language (as presented in the public schools of Kuwait).

\section{Methodology}

\subsection{The Sample}

The study was conducted on 244 Kuwaiti male (42.2\%) and female $(57.8 \%)$ Kuwaiti participants, undergraduate college students/graduates aged 18-30. The age gap between the participants and the college context where this study is applied meant that we could group participants into two categories 'younger' (18-21 undergraduate students) and 'older' (22-30 college graduates). The mean age of participants is 20 (24 for male participants and 20 for female participants). The accumulation of the 244 participants was done by snowball sampling, where participants with direct connection with the authors recruited people from their connections, allowing the researchers to gain some information about the participants beforehand (Goodman, 1961).

\subsection{Material}

The participants were sent a 48-questions test (shown in Appendix A). At the beginning of the test, two ethnographic questions were asked about age and gender. One additional question asked the students whether they were graduates of public or private schools to disregard the private schools so as not to add this variable due to its variable linguistic nature.

The 44 remaining questions consisted of one-syllable English words, in no particular order that started or ended with the 3 English (non-Arabic) consonants $/ \mathrm{p} /, / \mathrm{v} /$ and $/ \mathrm{t} \int /$ and their voiced/voiceless phonetic counterparts /b/, /f/, /J/. The $/ \mathrm{p} /$ and $/ \mathrm{v} /$ sounds do not exist in Kuwaiti Arabic, but $/ \mathrm{t} \mathrm{f} /$ does (but not in Egyptian or Syrian) and was tested to investigate the effect of orthography on perception since $/ \mathrm{t}$ / does not exist in written Arabic.

\subsection{Procedures}

The recordings were made on a Zoom $\mathrm{H} 1$ recorder in a sound-proof room and piloted on 20 male and female participants complying with the requirements set in the
"Sample" section. After two months, the same pilot group was given the test again, but with words instead of letters for a reliability test. No non-English words were used to avoid confusion. The example below explains the pilot test:

To test the [p] sound in the beginning of a word, in the first test, the participants hear the words "pin" once, and further away in the same test, he/she would hear the word "bin". The answer options provided in both questions were "p", "b", "v", and "f" randomly distributed. After two months, in the second test, the participants hear the same words ("pin" and "bin") but the choices this time are "bin", "pin", "chin" and "shin". By conducting a Cronbach test, the pilot study results were shown to be highly reliable, scoring 8.9 and 8.6 consecutively.

The researchers then conducted the study on 244 participants. The participants were asked to identify the letter perceived at the beginning or end of the words from a list of four letters (as performed in the pilot study), which consisted of the correct sound, it is voiced/voiceless counterpart, and two other random letters added for the following reasons:

Making sure the participants are listening to the recordings as the two other letters are almost impossibly correct.

Assuring that the answers are not chosen randomly, just to provide answers since with two sounds only, there would be a 50/50 chance that a random choice would be a correct choice.

Making sure the recordings were clear. The appearance of frequent wrong answers might suggest that the recordings were not clear.

The tests for the current research was conducted in 20182019 , students, and graduates from different universities and colleges in Kuwait.

\subsection{Analysis}

The results were analyzed via SPSS 16.0 to gain frequency, mean, and significance of the independent variables. The results were grouped and analyzed in sound groups, as shown in Figure 2 below.
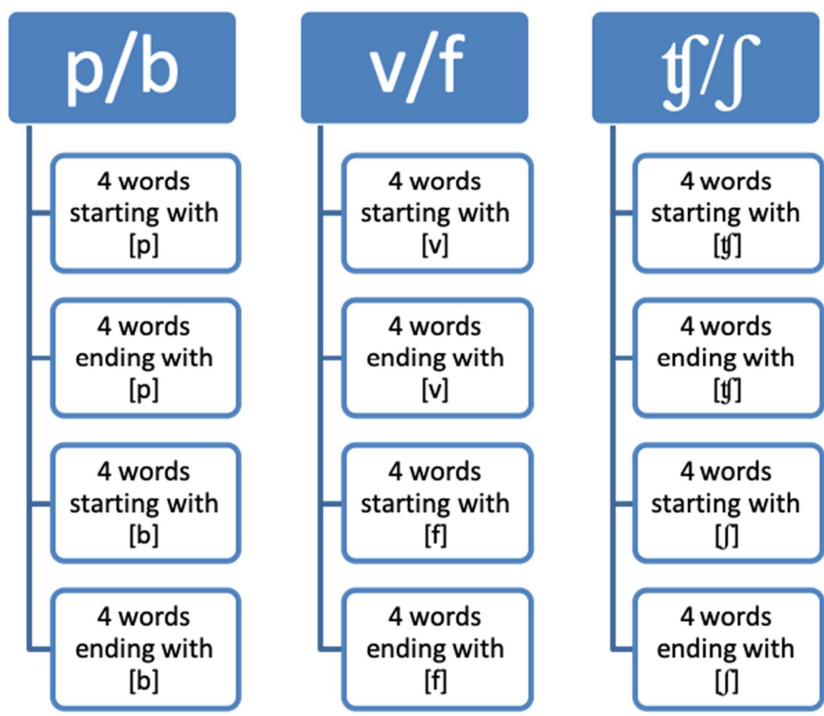

Figure 2. Sounds analysis. 


\section{Results}

The statistics analyzed the perception of English consonants and their voiced/voiceless counterpart in the beginning and end of one-syllable words, Table 1 lists the words recorded in the test.

Table 1. Words recoded in the perception test.

\begin{tabular}{llllll}
\hline $\mathbf{p} / \mathbf{b}$ & & $\mathbf{v} / \mathbf{f}$ & & $\mathbf{t}] /[$ & \\
\hline [p] & [b] & {$[\mathbf{v}]$} & [f] & $[\mathbf{t}]]$ & {$[j]$} \\
\hline pin & bin & vine & fine & chin & shin \\
par & bar & veal & feel & chore & shore \\
pain & brain & veil & fail & chance & shank \\
peep & beep & vast & fast & cheap & sheep \\
lap & lab & have & half & batch & bash \\
rope & robe & save & safe & match & mash \\
tap & tab & wave & waif & leech & leash \\
loop & lube & leave & leaf & pitch & pish \\
\hline
\end{tabular}

It was found from the analysis of the responses collected that $/ \mathrm{p} /$ was identified correctly $66.5 \%$ of the time, while $/ \mathrm{b} /$ was identified correctly $83 \%$ of the time. When analyzing the data further, It was found that $/ \mathrm{p} /$ was perceived as $/ \mathrm{b} /$ when it appeared at the beginning of the word $29 \%$ of the time. However, when $/ \mathrm{p} /$ appeared at the end of the words, it was identified as $/ \mathrm{b} / 38.1 \%$ of the time. On the other hand, when the words started with $/ \mathrm{b} /$, it was identified correctly $81.1 \%$ of the time (198 correct tokens), and it was also correctly perceived $85 \%$ word-end (203 tokens). Figure 3 below shows the difference between the correct perception of $/ \mathrm{p} /$ identification of $/ \mathrm{p} /$ and $/ \mathrm{b} /$ word-initial and word-end. A oneway ANOVA by age was conducted and reflected significance of $p=0.023$ and $p \geq 0.01$ (where significance is calculated at $\mathrm{p} \geq 0.05$ ) in the beginning and the end of words successively. The data showed that the older group perceived /b/ as /p/ mostly (mean 1.00 and 1.3 consecutively, where the average mean is 1.8 and 2.2 ).

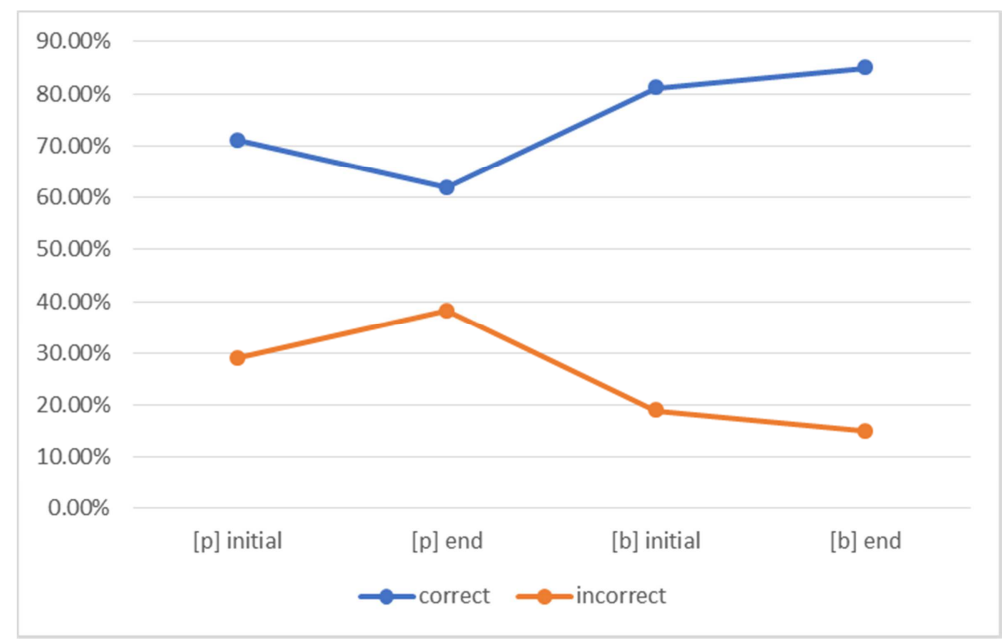

Figure 3. Correct perception of [p] and [b].

As for the perception of $/ \mathrm{v} /$ and $/ \mathrm{f} /$, the data shows that $/ \mathrm{v} /$ was correctly identified $75 \%$ when it occurred in initial position, $83.60 \%$ in final position. The phoneme /f/ was correctly identified $80.30 \%$ in initial position, $89 \%$ in final position. Overall, /V/ was correctly identify $79.3 \%$ of the time, and /f/ was correctly identified $84.7 \%$ of the time. A further investigation in the perception of these sounds shows that the participants had fewer incorrect answers when identifying $/ \mathrm{v} /$ than $/ \mathrm{p} /$. In a one-way ANOVA by age, significance was found at $\mathrm{p} \geq 0.01$ as the younger group (1821 years old) had significantly more correct answers where the mean was $\mathrm{m}=2.15$ and the average mean was 2.03 .

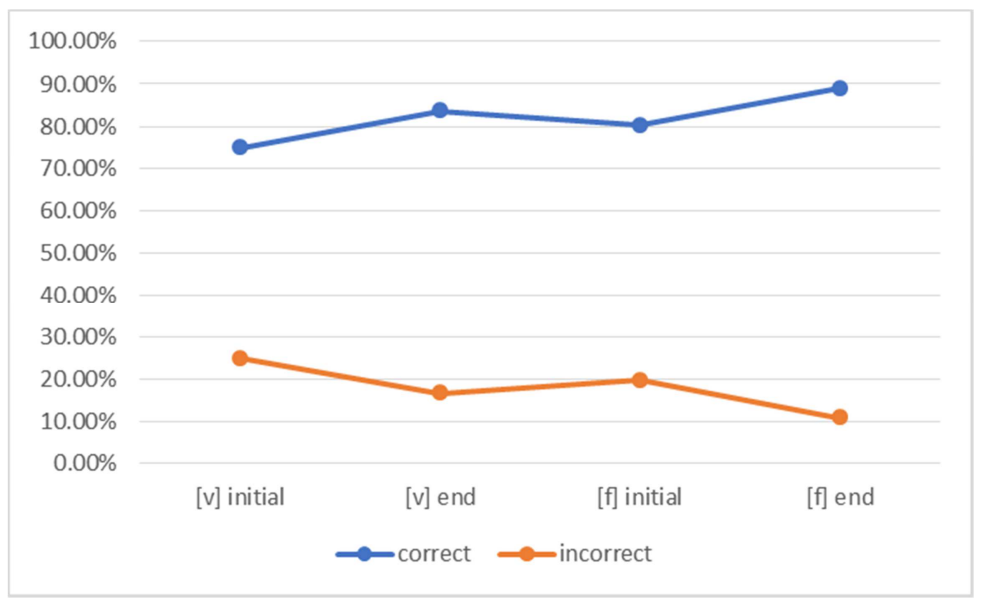

Figure 4. A representation of correct answers to words beginning and ending with $/ v /$ and $/ f /$. 
When the participants were listening to words that began and ended with $/ \mathrm{f} /$, they perceived it correctly in $88,2 \%$ of the words, showing a difference of less than $4 \%$ in comparison with their perception of $/ \mathrm{v} /$. The data clearly revealed that the students face fewer problems identifying $/ \mathrm{f} /$ and $/ \mathrm{v} /$ than the other sounds understudy in this research. However, /f/ was significantly correctly identified more when it appeared word-end ( $\mathrm{p} \geq 0.01)$. While /f/ was identified correctly when word-initial $83.4 \%$ of the time (222 tokens), it was correctly perceived word-end $92.9 \%$ of the time (247 tokens). In a two-way ANOVA by age by gender by the correct perception of the /f/ sound, significance was found at $\mathrm{p}=0.01$, as the older male participants perceived /f/ less correctly than their female counterpart $($ mean $=2.11$, average mean $=1.36)$.

The final English sound investigated was $/ \mathrm{t} /$, which was correctly perceived $81.8 \%$ of the time. Surprisingly, $/ \mathrm{t} \mathrm{f} /$ was identified incorrectly word-initial only $9.5 \%$ of the time $(23$ tokens). However, when presented word-end, it was identified incorrectly $27 \%$ of the time (66 tokens), which reflects clear significance calculated at $p \geq 0.01$. Significance was also found in a one-way ANOVA by gender by the identification of $/ \mathrm{t} /$ / word-end at $\mathrm{p}=0.02$. This was found as female participants significantly identified $/ \mathrm{t} / /$ word-initial more than male participants (mean was calculated at 2.40 and 2.13 respectively). The participants had more trouble identifying / / / correctly (79.3\%). Besides, as the case with $/ \mathrm{v} /$, they identified $/ \mathrm{J} /$ word-initial correctly only $74.6 \%$ of the time (182 tokens). When analyzing the data of the $/ \mathrm{J} /$ sound when it occurred at the end of the word, it was found that the participants identified it less than when identified at the beginning of the word ( $84 \%)$. This reflects that the place of the consonant has an insignificant effect on its perception. Figure 5 represents the correct/incorrect perception of $/ \mathrm{t} f /$ and /J/ overall.

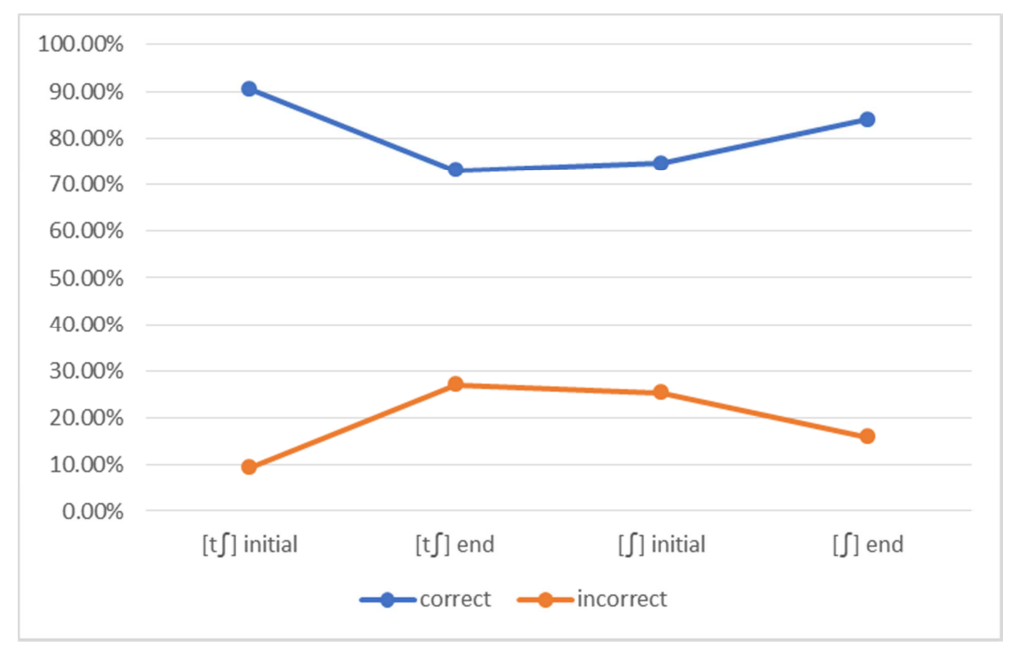

Figure 5. The perception of $/ \mathrm{t} / \mathrm{a}$ and $/ \mathrm{f} /$.

All in all, the data has shown that in the case of $/ \mathrm{p} /, / \mathrm{v} /$ and $/ \mathrm{t} \mathrm{f} /$, the place of the consonant affected their perception. While $/ \mathrm{p} /$ and $/ \mathrm{t} \mathrm{f} /$ were correctly perceived more when they appeared at the beginning of the word, / $/$ was identified correctly more when it appeared at the end of the word. Besides, all the English sounds were identified incorrectly more than their counterpart, yet, significance was only found when comparing the perception of $/ \mathrm{p} /$ and $/ \mathrm{b} /(\mathrm{p} \geq 0.01)$ as $/ \mathrm{p} /$ which was generally incorrectly perceived $33.5 \%$ of the time and $/ \mathrm{b} /$ was perceived incorrectly $17 \%$ of the time.

\section{Discussion}

In this article, we attempt to shed the light on three research hypotheses: 1) L2 learners skills in accurately perceiving L2 consonants would more likely be affected by the similarity/dissimilarity concept proposed in various influential phonological awareness theories in the literature of SLA; 2) Similarity/dissimilarity and L1 orthography intertwine in how L2 learners mirror L2 consonants; 3) the structural hypercorrection as identified in the field of SLA [30], sociolinguistics [28], as well as in historical linguistics
[41] simulated in L2 contrasting phoneme system.

The present study looks specifically into the phonological errors made by Kuwaiti speakers of English when L1 has a parallel phoneme of only one of the two contrasting L2 phonemes in its L1 phoneme and/or orthography, namely /p/ and $/ \mathrm{b} /, / \mathrm{v} /$ and $/ \mathrm{f} /$, and finally $/ \mathrm{t} / /$ and $/ \mathrm{J} /$. It should be noted here that Arabs (including Kuwaitis) live in typical diglossic communities [42], where the speakers are introduced to several spoken regional vernaculars employed in their everyday speech, that coexist with a spectrum of high standardized language varieties practiced only in formal contexts [43]. In Kuwait, the community follows a similar diglossic pattern, where the various language varieties represent variable phonological, syntactic and lexical structures. Sub-linguistic structures do also exist within Kuwaitis based on the regional origins from where they immigrated [38].

The findings of the study present a variation in the frequency of accurate perception of $/ \mathrm{p} /$ and $/ \mathrm{b} /(71 \%$ and $81 \%$ ) when the two consonants appear in initial positions respectively, and $(61 \%$ and $85 \%)$ when the consonants appear in word-final position. Also /v/ and /f/ were $75 \%$ and 
$80.30 \%$ respectively, accurately perceived in initial position; but were $83.60 \%$ and $89 \%$ when they occur at word-final position. This finding tends to be in line with previous studies indicating the higher vulnerability of sounds when they occur in initial rather than final word positions, following an injury to the brain [44], as well as in normal individuals, because word-initial consonants are processed separately from subsequent consonants [45]. The findings also suggest that the English voiced-voiceless contrast, nonexisting in the L1 phoneme system, would not be treated as a novel phonemic contrast, which implies the significance of teaching the new phonemic system on an allophone-byallophone ground. Our investigation has additionally presented that participants belonging to the older category (22-30-year-old group, see Section 3.1) have significantly underperformed their younger counterparts (18-21-year-old group). The finding signals an adequate amount of progression taking place in the Kuwaiti community in terms of their abilities to properly perceive non-existing English contrasting phonemes in their L1. Similarity/dissimilarity seems also to be at work. As predicted in SLM [12], Kuwaiti learners of English tend to establish an L2 phonetic category representation for sounds in the $\mathrm{L} 2$, which does not correspond to their L1 categorical representation. And as the perceived phonemic dissimilarity of $/ \mathrm{p} /$ and $/ \mathrm{v} /$ is not as distinctive as they should be from the closest L1 sounds, namely /b/ and /f/, new categories for the two L2 consonants were not created, causing a confusion between non-existing L2 consonants and their existing counterparts in L1.

The finding also verifies PAML2 postulations, whereby the two L2 sounds $(/ \mathrm{p} / \& / \mathrm{v} /)$ are assimilated to a single L1 category $(/ \mathrm{b} / \& / \mathrm{f} /)$ respectively, and as a result, establishes poor discrimination between L2 and the closest L1 counterparts. Kuwaiti learners tend to be in the process of moving from (Full copying) into (Full access) as a result of high exposure to L2 in the media [39]. Nevertheless, they have not reached the level of (Full proficiency), where L1 and L2 are expected to constitute two separate sets of perceptual phonological categories.

From another angle, the findings present that /f/ has been perceived as $/ \mathrm{v} / 19.70 \%$ of the time when appeared in wordinitial position, but $11 \%$ only in word-final position. The phoneme /b/ was misperceived as /p/ in around $19 \%$ and $15 \%$ of the cases in word-initial and word-final position, respectively. In both phonemes, $/ \mathrm{b} /$ and $/ \mathrm{f} /$, incidents of perceiving them as $/ \mathrm{p} /$ and $/ \mathrm{v} /$ might imply a case of hypercorrection, where the subject tends to amplify a phoneme recognition in environments where the phoneme should not be in effect. Younger female subjects tend to significantly intensify such tendency (hypercorrection) when compared to the older male counterparts. The finding could be possibly explained via Labov's gender paradox theory of overt prestige, stating that 'women conform more closely than men to sociolinguistic norms that are overtly prescribed, but less than men when they are not' [46]. Having associated the target language phoneme system with linguistic prestige in SLA, our female subjects' performance tends to correspond to a robust conclusion of gender variation in contemporary sociolinguistics, not only in L2 production but also in L2 perception.

Following the stance of Eckman et al (2003), the study's findings tend to challenge associating such incidences of over-perception of L1 phonemes to L2 non-existing counterparts with 'crosslinguistic influence' [29-30] or 'overgeneralization' [32]. That is to say, it would be irrational to assume that the realization of $/ \mathrm{f} /$ and $/ \mathrm{b} /$ as $/ \mathrm{v} /$ and $/ \mathrm{p} /$ is originated in Kuwaiti learners' L1 (where the two phonemes do not appear in their L1 inventory). If the L1 phonological categorization has been followed in this case, the phonemes $/ \mathrm{v} /$ and /p/ should never appear in Kuwaitis' phonological system. Likewise, the over-perception of the two phonemes should not be equated to overgeneralization, since neither L1 nor L2 phonemic inventories alternate between $/ \mathrm{p} /$ and $/ \mathrm{v} /$ and their counterparts $/ \mathrm{b} /$ and $/ \mathrm{f} /$. Besides, when bearing in mind that our data showed female informants significantly tended to amplify such pattern; it could logically indicate that a prestige pattern seemed to be sought after by our female informants.

In relation to the concept of hypercorrection, Eckman et al. argue, 'a learner must necessarily have the contrast in question, at least to some extent, before the contrast can be hypercorrected' [47]. Also, based on the views reporting that hypercorrection errors may well be the product of 'linguistic insecurity' and the relative prestige attached to the target language in SLA contexts, it would be reasonable to state that hypercorrection emerges whenever the L2 learner is faced with the novelty of the introduced lexemes containing the phonemic contrast in question. As a consequence, Eckman and his co-investigators claim that incidences of hypercorrection errors could indicate that an L2 learner has successively reached the final stage in the acquisition of the target language phonemic contrast.

When considering Eckman and his associates' claims, the community under investigation seems to have relatively reached a near-intelligible perception of the problematic contrasting sounds $(/ \mathrm{P} /$ and $/ \mathrm{b} / ; / \mathrm{v} /$ and $/ \mathrm{f} /)$ of the target language (English in our case) as acquired by Kuwaitis. Rather than viewing those incidences of hypercorrections as emerging linguistic difficulties taking place in the field of SLA, we propose that such hypercorrection instances should be considered as a positive learning outcome that signals the likelihood of the community moving towards an intelligible phoneme contrast competency.

The variable findings in the present study suggest that younger female individuals seem to gain much more advanced perceptive abilities along with the tasks of contrasting phonemes of English. Future studies might explore reasons for such advancement.

As for the two voiceless affricates $/ \mathrm{t} / /$ and $/ \mathrm{J} /$, our findings point to less problematic perceptions of both phonemes that are correctly perceived $90.50 \%$ and $63 \%$, respectively in word-initial position, $73 \%$ and $84 \%$ in word-final position. It should be noted at this point that both $/ \mathrm{t} / \mathrm{f}$ and $/ \mathrm{d} / \mathrm{do}$ exist in Kuwaitis' L1 phonological inventory. Still, some level of 
confusion did appear in the findings, which could possibly be related to the learners' L1 orthography system. It should also be borne in mind that Kuwaitis, like all other Arabs, speak a language which they do not write, and write a language that they do not speak, a situation that has been typically described as diglossic (see Section 2.4). Therefore, even though Kuwaitis have no phonological constraints that originate from their unfamiliarity with the phoneme $/ \mathrm{t} /$, our findings prove that they do encounter perception problems in phonemes that are missing from their orthography, namely $/ \mathrm{t} / \mathrm{l}$. Hence, rather than considering orthographical features as 'noise in the data', the influence of orthography should be thoroughly investigated in any future phonological research.

\section{Conclusion}

This article reports empirical findings based on the investigations into L2 phonemic contrasts within the linguistic setting in Kuwait. In an attempt to find out whether adequate L2 phoneme perception would lead to intelligible contrasting phonemic distinction, the findings of the study suggest that Kuwaiti learners of English encounter complications at a deeper level due to the existence of several contrasting phonemes in both L1 and L2. In other words, when two contrasting phonemes occur in L2 that have identical counterparts in L1, but variable phonemic representations, the learnability of the contrasting phonemes will exert major problematic issues in the perception of the sounds in question. A similar conclusion has been proposed and verified in the context of Korean learners of English [47]

Another finding is related to the concept of hypercorrection and the reasons behind its occurrence. From a merging sociolinguistic/second language acquisition perspective, phonemic hypercorrection is an instance that might probably take place at a higher level of phonemic competence of L2, due to the acquired ability to distinguish between contrasting phonemes that hold similar features of the phonemic features of L1, and as a result of L2 learners perceiving the target language as a relative entity for prestige. When L2 learners seek the linguistic prestige associated with the target language phoneme system, second language learners will, not only adapt the target language phoneme system but also overextends that system to environments beyond the L2 system. Whether the linguistic transfer and hypercorrection will be mapped into the production of the contrasting phonemes is another story that should be explored in a subsequent independent study.

The study also asserts that the orthography system of Kuwaitis' L1 influences how accurate they perceive L2 phonemes. Hence, the learners' familiarity with L2 phonemes should not only be mapped into the learners' phonological inventory but also L1 orthographical features, both twining together to mirror the learners' L1 in how accurate they perceive the L2 phonological system.

Some limitations should be accounted for at this point. The first is that our experimental investigation has not looked into the contrasting phonemes in word-medial position. Further studies are recommended to explore the issue in word-medial position and find out if different conclusions would be reached when compared to word-initial/final positions.

A correlation between hypercorrection and crosslinguistic influence could have been utilized to reflect on whether the incidences of hypercorrection have been performed by the subjects who experienced phonemic language transfer. A follow-up study might look more independently into the relationship between language transfer and hypercorrection as different levels of phonemic L2 acquisition.

\section{References}

[1] Morley, J. (1991). The pronunciation component in teaching English to speakers of other languages. TESOL quarterly, 25 (3), 481-520.

[2] Iverson, P., Kuhl, P. K., Akahane-Yamada, R., Diesch, E., Tohkura, Y. I., Kettermann, A., \& Siebert, C. (2003). A perceptual interference account of acquisition difficulties for non-native phonemes. Cognition, 87 (1), B47-B57. 10.1016/S0010-0277(02)00198-1.

[3] Bley-Vroman, R. (1989) The logical problem of second language acquisition. In S. Gass and J. Schachter (eds.), Linguistic Perspectives on Second Language Acquisition, pp. 41-72. Cambridge: Cambridge University Press. 20. 10.1017/CBO9781139524544.005.

[4] Briere, E. (1966). An investigation of phonological interference. Language. 42: 769-96.

[5] Flege, J. E. (1981). The phonological basis of foreign accent. TESOL Quarterly. 15: 443-55.

[6] Wode, H. (1992) Categorical perception and segmental coding in the ontogeny of sound systems: A universal approach. In C. Ferguson, L. Menn and C. Stoel-Gammon (eds.), Phonological Development: Models, Research, Implications, pp. 605-31. Baltimore: York Press.

[7] Brown, C. (2000). The interrelation between speech perception and phonological acquisition from infant to adult. In: Archibald J, editor. Second language acquisition and linguistic theory. Malden, MA: Blackwell; 2000. Pp. 4-63. [Google Scholar].

[8] Akbar, R. (2019). Arabizi Among Kuwaiti Youths: Reshaping the Standard Arabic Orthography. International Journal of English Linguistics 9 (1): 301.

[9] Dashti, A. (2015). The role and status of the English language in Kuwait. English Today, 31 (03): 28-33. DOI: 10.1017/S026607841500022X.

[10] Isbell, D. (2016). The Perception-Production Link in L2 Phonology. MSU Working Papers in SLS 2016, Vol. 7 ISBELL - PERCEPTION-PRODUCTION LINK.

[11] Best, C. T., \& Tyler, M. (2007). Nonnative and second-language speech perception. Language experience in second language speech learning: In honour of James Emil Flege, 13-34.

[12] Flege, J. E. (1995). Second language speech learning: Theory, findings, and problems. In W. Strange (Ed.), Speech perception and linguistic experience: Issues in cross-language research (pp. 233-276). Timonium, MD: York Press. 
[13] Flege, J. E., \& MacKay, I. R. A. (2004). Perceiving vowels in a second language. Studies in Second Language Acquisition, $26,1-34$.

[14] Weinreich, U. 1957. On the description of phonic interference. Word 13: 1-11.

[15] Flege, J. E. (2003). Assessing constraints on second-language segmental production and perception. In A. Meyer \& N. Schiller (Eds.), Phonetics and phonology in language comprehension and production: Differences and similarities (pp. 319-355). Berlin: Mouton de Gruyter.

[16] Takagi, N. 1993. Perception of American English /r/ and /1/ by adult Japanese learners of English: A unified view. Unpublished Ph.D dissertation, University of California-Irvine.

[17] Best, C. T. \& Strange, W. (1992). Effects of phonological and phonetic factors on cross-language perception of approximants. Journal of Phonetics, 20, 305-330.

[18] Escudero, P. (2007). Second language phonology: The role of perception. In book: Phonology in Context (pp. 109-134). DOI: 10.1057/9780230625396_5.

[19] Grosjean, F. (2001). The Bilingual's Language Modes. In J. L. Nicol (Ed.), Explaining linguistics. One mind, two languages: Bilingual language processing (p. 1-22). Blackwell Publishing.

[20] Pennington, M. C. (1996). Phonology in English language teaching: An international approach. New York, NY: Longman.

[21] Bassetti, B. (2017). Orthography affects second language speech: Double letters and geminate production in English. Journal of Experimental Psychology: Learning, Memory, and Cognition, 43 (11), pp. 1835-1842. DOI: $10.1037 / x \operatorname{lm} 0000417$.

[22] Silveira, R. (2012). PL2 production of english word-final consonants: the role of orthography and learner profile variables. Trabalhos em Linguística Aplicada. 51. 13-34. 10.1590/S0103-18132012000100002.

[23] Sipra, M. (2013). Contribution of Bilingualism in Language Teaching. English Language Teaching. 6 (3), 116-124. Doi: 6. 56. 10.5539/elt.v6n1p56.

[24] Sokolović-Perović, M., Bassetti, B., \& Dillon, S. (2019). English orthographic forms affect L2 English speech production in native users of a non-alphabetic writing system. Bilingualism: Language and Cognition, 1-11. 1-11. 10.1017/S136672891900035X.

[25] Zampini, M. L. (1994). The Role of Native Language Transfer and Task Formality in the Acquisition of Spanish Spirantization. Hispania, 77 (3), 470-481. doi: $10.2307 / 344974$.

[26] Kenworthy, J (1987), Teaching English Pronunciation, Longman Handbooks for Language Teachers, Longman, London and New York.

[27] Showalter, C. E., \& Hayes-Harb, R. (2013). Unfamiliar orthographic information and second language word learning: A novel lexicon study. Second Language Research, 29 (2), 185-200. https://doi.org/10.1177/0267658313480154

[28] Labov, W. (1972). Sociolinguistic patterns (No. 4). University of Pennsylvania Press.
[29] Odlin, T. (1989). Language Transfer: Cross-Linguistic Influence in Language Learning. Cambridge: Cambridge University http://dx.doi.org/10.1017/CBO9781139524537

[30] Janda, R. \& Auger, J. (1992). Quantitative Evidence, Qualitative Hypercorrection, Sociolinguistic Variables--And French Speakers'"'eadhaches" with English h/O. Language and Communication. 12. 10.1016/0271-5309(92)90015-2.

[31] Eckman, F. R., Elreyes, A., \& Iverson, G. K. (2003). Some principles of second language phonology. Second Language $\begin{array}{llll}\text { Research, } & 19 & \text { (3), } & 169-208 .\end{array}$ $10.1191 / 0267658303 \mathrm{sr} 2190 \mathrm{a}$.

[32] Siegel, J. (2003). Substrate influence in creoles and the role of transfer in second language acquisition. Studies in Second Language Acquisition 25 (2), 185-209.

[33] John, P. and Cardoso. W. (2008). Francophone ESL learners and $[\mathrm{h}]$-epenthesis. Concordia Working Papers in Applied Linguistics, 1 (76-97).

[34] Nickerson, C. and Camiciottoli, B. C. (2013). Business English as a Lingua Franca in advertising texts in the Arabian Gulf: Analyzing the attitudes of the Emirati Community. Journal of Business and Technical Communication. 27 (3): 329-352. DOI: 10.1177/1050651913479930.

[35] Shafiro, V., Levy, E. S., Khamis-Dakwar, R. \& Kharkhurin, A. (2013). Perceptual confusions of American-English vowels and consonants by native Arabic bilinguals. Language and Speech. 56 (2): 145-6. DOI: 10.1177/0023830912442925.

[36] Alshangiti, W. M. M. (2015). Speech production and perception in adult Arabic learners of English: A comparative study of the role of production and perception training in the acquisition of British English vowels (Doctoral dissertation, UCL (University College London).

[37] Horn, C. (2015) Diglossia in the Arab World - Educational implications and future perspectives. Open Journal of Modern Linguistics, 5: 100-104. DOI: 10.4236/ojml.2015.51009.

[38] Taqi, H. (2010). Two ethnicities, three generations: Phonological variation and change in Kuwait (Doctoral dissertation, Newcastle University).

[39] Algharabali, N. \& Taqi, H. (2018) Performing Speaking "Ungrammatical" American English: A Kuwaiti Linguistic Phenomenon. Open Journal of Modern Linguistics. Vol. 8, 242-261.

[40] Dashti, A. (1997). Language choice in the State of Kuwait: A sociolinguistic investigation. $\mathrm{PhD}$ dissertation. Essex: University of Essex.

[41] Cambell, L. (1998). Historical Linguistics: An Introduction. Edinburgh University Press: Edinburgh. $7^{\text {th }}$ edition.

[42] Ferguson, C. A. (1959). Diglossia. Word, 15 (2) 325-340. DOI: 10.1080/00437956.1959.116597/02.

[43] Almousawi, H., BinAli, S. and Alqallaf, B. (2019). Linguistic awareness and knowledge among prospective English teachers in Kuwait: Implications in inclusive classrooms. Journal of Educational and Social Research, 9 (3): 125-138.

[44] Kent, R. D. and Rosenbek, J. C. (1983). Acoustic patterns of apraxia of speech. Journal of Speech, Language and Hearing, 26: 231-249. 
[45] Shattuck-Hufnagel, S. (1979). Speech errors as evidence for a serial-ordering mechanism in sentence production. In: Sentence processing: Psycholoinguistic Studiespresented to Merrill Garrett, W. E. Cooper \& E., C. T. Walker (eds) Lawrence Erlbarum.

[46] Labov, W. (2001). Principles of Linguistic Change, Vol 2: External factors. Oxford: Blackwell.
[47] Eckman, F. R., Iverson, G. K. and Song, J. Y. (2013). The role of hypercorrection in the acquisition of L2 phonemic contrasts. Journal of Second Language Research, 29 (3), p. 257-283. 